\title{
ANALISIS BIAYA PEMELIHARAAN DAN PERAWATAN KANTOR PELAYANAN BEA DAN CUKAI PEKANBARU
}

\author{
Weno Dwirafi Nizki ${ }^{1}$, Zainuri $^{2}$, Widya Apriani ${ }^{3}$ \\ 1,2,3 Program Studi Teknik Sipil, Fakultas Teknik, Universitas Lancang Kuning \\ Jl. Yos Sudarso km. 8 Rumbai, Pekanbaru, Telp. (0761) 52324 \\ Email: wenodwirafinizki23@gmail.com, zainuri@unilak.ac.id,widya@unilak.ac.id
}

\begin{abstract}
ABSTRAK
Keberadaan bangunan gedung mempunyai peranan penting dalam kehidupan manusia sesuai tujuan dibangunnya bangunan tersebut. Setelah selesai dibangun suatu bangunan diharap kan mampu menjalankan fungsinya sesuai umur rencana. Tujuan penelitian ini untuk mengestimasi biaya pemeliharaan dan perawatan pada Kantor Pelayanan Bea dan Cukai Pekanbaru menurut PERMEN NO.24/PRT/M/2008. Diharapkan dengan adanya sistem ini, kegiatan penanganan pemeliharaan dan perawatan berada pada kondisi sesuai standar yang berlaku dan mempertahan kegunaan serta nilai dari bangunan tersebut. Peraturan Menteri Pekerjaan Umum Nomor: 24/PRT/M/2008 tentang pedoman pemeliharaan dan Perawatan Bangunan Gedung, pemeliharaan gedung Penelitian ini dilakukan dengan metode Estimasi Harga Prakiraan (approximate estimate) yaitu menggunakan harga satuan tertinggi rata-rata per- $\mathrm{m}^{2}$ bangunan bertingkat untuk bangunan gedung yang akurat sebagai pedoman. Hasil perhitungan penelitian ini didapat biaya estimasi harga perkiraan taksiran kasar (approximate estimate) sebesar Rp.16.156.679,93,- jika dibandingkan dengan perhitungan harga bangunan sebesar Rp.11.483.051,200,- persentase biaya untuk perawatan pemeliharaan bangunan Kantor Pelayanan Bea Cukai Pekanbaru hanya sebesar 0,1407\% dari total harga bangunan, Sehingga dapat dikategorikan dalam tingkat kerusakan ringan $(<35 \%)$. Sedangkan untuk biaya pemeliharaan per-tahunnya adalah sebesar Rp. 319.792.000,00,- di tahun 2020 yang diperkirakan akan meningkat setiap tahunnya mengacu pada nilai inflasi berdasarkan Bank Indonesia
\end{abstract}

Kata Kunci: Estimasi, Pemeliharaan, Perawatan, Perkantoran

\begin{abstract}
The existence of buildings has an important role in human life according to the purpose of the building. After completion of a building is expected to be able to carry out its functions according to the age of the plan. The purpose of this study is to estimate the cost of maintenance and care at the Pekanbaru Customs and Excise Service Office based on PERMEN NO.24 / PRT / M / 2008. It is expected that with this system, maintenance and maintenance activities will be in accordance with applicable standards and retain the use and value of the building. Regulation of the Minister of Public Works Number: 24 / PRT / M / 2008 concerning guidelines for building maintenance and maintenance, building maintenance This research was conducted using the Approximate Estimate method using the highest average unit price per $m^{2}$ of storey buildings for buildings accurate building as a guideline.he results of the calculation of this study found the estimated cost estimate of rough estimate (approximate estimate) of Rp. 16.156.679,93, - when compared with the calculation of the building price of Rp. 11.483.051,200 - the percentage of costs for maintenance of buildings in Pekanbaru Customs Service Office is only 0,1407\% of the total price of the building, so that it can be categorized in the level of minor damage (<35\%). Whereas the annual maintenance fee is $R p$. 319.792.000,00, - in 2020 which is expected to increase every year based on the value of inflation based on Bank Indonesia.
\end{abstract}

Keywords: Estimation, Maintenance, Maintenance, Offices spase

\section{PENDAHULUAN}

Gedung Bea dan Cukai yang berlokasi di Jalan Jenderal Sudirman Nomor 2-4, Kampung Dalam Senapelan merupakan satu dari Kantor Pelayanan Bea dan Cukai yang bertempat di Kota Pekanbaru. Gedung Bea dan Cukai ini di resmikan pada tahun 2011. Untuk mencapai kondisi yang demikian, bangunan prasarana dan peralatan tersebut harus dikelola dengan baik, efektif dan efisien. Pengelolahan tersebut dimulai sejak perencanaan, pengadaan, operasional dan pemeliharaan termasuk di dalam pengamanan dan penghapusannya. 
Berdasarkan Peraturan Menteri Pekerjaan Umum Nomor 24/PRT/M/2008 tentang pedoman pemeliharaan dan perawatan bangunan gedung, bangunan gedung merupakan wujud fisik hasil pekerjaan konstruksi yang sudah menyatu dengan tempat kedudukannya, sehingga manusia melakukan kegiatannya, baik untuk hunian atau tempat tinggal, kegiatan keagamaan, kegiatan usahan, kegiatan social, budaya, maupun khusus, dan bagunan tersebut sebagian atau seluruhnya berada di atas atau di dalam tanah dan air.

kegiatan yang dilakukan untuk menjaga, memperbaruhi dan juga pemperbaiki semua fasilitas yang ada sebagai bangunan agar tetap berada pada kondisi sesuai standar yang berlaku dan mempertahan kegunaan serta nilai dari bangunan tersebut disebut dengan pemeliharaan. Karena pada dasarnya bangunan juga harus mendapatkan pemeliharaan yang baik.

Berdasarkan latar belakang maka akan dilakukan suatu penelitian untuk menganalisis kerusakan komponen bagian gedung dan mengestimasi biaya pemeliharaan dan perawatan gedung kantor pelayanan Bea dan Cukai Pekanbaru, supaya bangunan yang di bangun tentunya juga harus mendapatkan skala prioritas penanganan pemeliharaan pada bangunan kantor pelayanan Bea dan Cukai Pekanbaru. Dengan melakukan pemeliharaan dan perawatan berdasarkan Permen Pekerjaan Umum Nomor : 24/PRT/M/ 2008 dan Pembangunan Bangunan Gedung Negara berdasarkan Permen Pekerjaan Umum Nomor : 22/PRT/M/2018. Harapannya dengan adanya sistem ini, suatu penanganan pemeliharaan dan perawatan gedung berada pada kondisi sesuai standar yang berlaku serta mempertahan kegunaan dan nilai dari bangunan tersebut.

\section{METODE PENELITIAN}

\subsection{Lokasi Penelitian}

Lokasi penelitian akan dilakukan di Kantor Pelayanan Bea dan Cukai Pekanbaru di Jalan Jenderal Sudirman Nomor 2-4, Pekanbaru - Riau

\subsection{Tahap Pengambilan Data}

Prosedur pengambilan data adalah cara untuk mengakumulasi data. Prosedur pengambilan data merupakan suatu cara sehingga dapat diperlihatkan penerapannya melalui studi linteratur,data sekunder ,dan data primer teknik pengumpulan data terhadap penelitian ini sebagai berikut :

1. Studi Linteratur

Prosedur dalam hal ini yaitu mencari bahan referensi berupa buku dan jurnal yang membahas tentang ketentuan-ketentuan teori serta rumusrumus yang turut berkontribusi dalam penulisan tugas akhir ini.

2. Data Primer

Data primer yang digunakan dalam penelitian penulisan tugas akhir ini didapat dari data kerusakan non-struktur yang di identifikasi di lapangan dan data as built drawing bangunan Gedung Kantor Pelayanan Bea dan Cukai Pekanbaru,

3. Data Sekunder

Data sekunder yang digunakan dalam penelitian penulisan tugas akhir ini didapat dari lembaga atau instansi berupa HSBGN Kota Pekanbaru terbaru, Harga satuan upah dan bahan Kota Pekanbaruterbaru, Dan data laporan inflasi (indeks harga konsumen) dari Januari 2018 sampai November 2019 yang di dapatdari Bank Indonesia.

\subsection{Metode Analisis Data}

Metode analisis data yang di butuhkan dalam penelitian ini, sebagai berikut:

1. Menganalisis suatu biaya perawatan atau perbaikan diperlukan pendekatan estimasi harga bangunan dengan menggunakan Harga Satuan Upah dan Bahan yang di peroleh dari harga pasaran di Kota Pekanbaru dan Rencana Anggaran Biaya (RAB), Sebagai beriku :

a. Perhitungan volume bersifat luasan $\left(\mathrm{m}^{2}\right)$ Untuk perhitungan volume suatu pekerjaan yang bersifat luasan digunakan rumus perhitungan sebagai berikut :

$\mathrm{V}=\mathrm{P} \times \mathrm{L}$

Keterangan :

$\mathrm{V}=$ Volume pekerjaan yang bersifat luasan

$\mathrm{P}=$ Panjang objek $(\mathrm{m})$

$\mathrm{L}=$ Lebar objek $(\mathrm{m})$

b. Perhitungan Rencana Anggaran Biaya (RAB) Untuk perhitungan anggaran biaya suatu pekerjaan digunakan rumus perhitungan sebagai berikut :

Anggaran Biaya = V x Harga Satuan (2.2)

Keterangan :

$\mathrm{V}=$ Volume

2. Menganalisa nilai peroyek digunakan estimasi harga perkiraan taksiran kasar (approximate estimate) dengan penggunaan metode pendekatan harga bangunan tertinggih. Karna standar biaya selanjutnya, menurut Permen PU NO.22/PRT/M/2018 dalam menenukan harga bangunan digunakan persamaan matematis sebagai berikut.

Harga per lantai $=B P x F x$

Dimana :

$\mathrm{BP}=$ Harga bangunan per $\mathrm{m}^{2}$

$\mathrm{F}=$ Faktor pengali bangunan ber - iat

$\mathrm{L}=$ Luas bangunan per-lantai

3. Menganalisa biaya kerusakan yang terjadi serta presentasenya. berdasarkan permen PU No,22/PRT/M/2018 tentang Pedoman Teknis Pembangunan bangunan gedung Negara. Adapun 
menghitung Persentase Kerusakan dengan Harga

Tertinggih sebagai berikut :

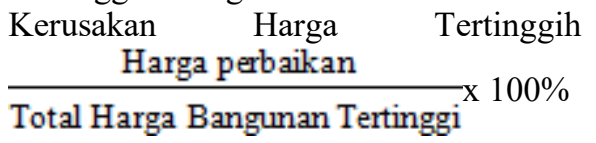

4. Merumuskan biaya pemeliharaan yang diperlukan bangunan Kantor Pelayanan Bea dan Cukai Pekanbaru, untuk 10 tahun kedepan.Adapun persamaan yang dipakai untuk menentukan nilai inflasi yaitu persamaan regresi liner maka regresi linier berdasarkan sampel dirumuskan sebagai berikut :

$Y=a+b x$

Keterangan :

$Y=$ nilai yang diukur/dihitung pada variabel tidak bebas

$x=$ nilai tertentu dari variabel bebas

$a=$ intersep/ perpotongan garis regresi dengan sumbu y

$b=$ koefisien regresi / kemiringan dari garis regresi / untuk mengukur kenaikan atau penurunan y untuk setiap perubahan satu-satuan $\mathrm{x}$ / untuk mengukur besarnya pengaruh $\mathrm{x}$ terhadap y kalau x naik satu unit. Untuk mencari faktor bunga majemuk menggunakan cara interpolasi dimana interpolasi itu merupakan teknik mencari harga suatu fungsi pada suatu titik diantara 2 titik yang nilai fungsi pada ke-2 titik tersebut sudah diketahui.(Mangitung, 2013)

Adapun persamaan interpolasi linear untuk mencari faktor bunga majemuk pada periode tahun pertama adalah :

$$
\begin{aligned}
& p 1(x)=\frac{(x-x 1)}{(x 0-x 1)} \cdot y 0+ \\
& \frac{(x-x 0)}{(x 1-x 0)} \cdot y 1
\end{aligned}
$$

Memprediksi jumlah anggaran biaya pemeliharaan ditahun yang akan datang menggunakan rumus bunga untuk pembayaran tunggal ( mencari F jika diketahui P ), penurunan rumusnya sebagai berikut :

Jika uang sejumlah $\mathrm{P}$ diiventasikan saat ini $(\mathrm{t}=0)$ dengan tingkat bunga efektif sebesar $\mathrm{i} \%$ per periode dan dimanajemukakan tiap periode maka jumlah uang tersebut pada waktu akhir periode 1 akan menjadi (Puryani, Agus, R., 2011).

$$
F \quad=P(F / P, i \%, n
$$

Dengan :

$F=$ Nilai mendatang ( future value), nilai ekuivalen dari satu atau lebih aliran kas pada suatu titik yang didefinisikan sebagain waktu mendatang.

$P=$ Nilai sekarang ( present value ) atau nilai ekuivalen dari satu titik atau lebih aliran kas pada suatu titik yang didefinisikan sebagai waktu saat ini.
i $=$
Tingkat bunga efektif per periode
$n=$ Jumlah periode pemajemukan

\subsection{Bagan Alir Penelitian}

Langkah-langkah yang diambil untuk mendukung proses penelitian yang akan dibuat agar penelitian dapat berjalan lebih terarah dan sistematis disebut dengan tahapan penelitian. Tahapan-tahapan penelitian dapat dilihat pada gambar 1 .

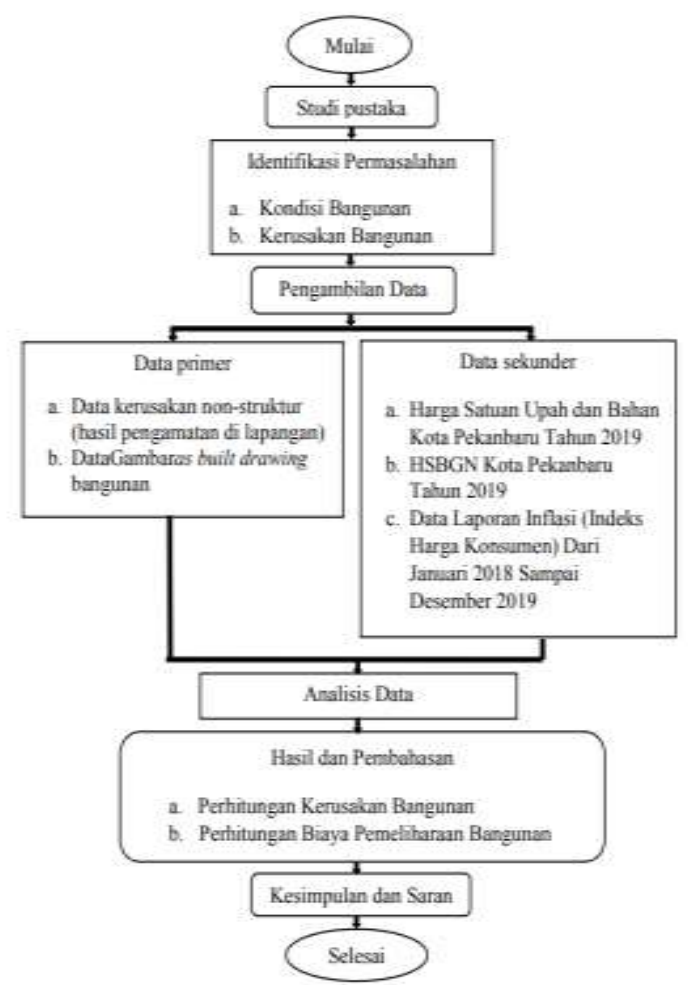

Gambar 1 Bagan Alir Penelitian

\section{HASIL DAN PEMBAHASAN}

Menurut hasil perhitungan biaya perawatan semua komponen arsitektur didapatkan nominal Rp.16.156.679,93,- dengan anggaran biaya perawatan terbesar terletak pada pekerjaan dinding, yaitu Rp.6.884.427,76,-. Komponen cat dinding wajib di perbarui minimal 3 tahun sekali, dikarenakan gedung tersebut berumur kurang lebih 5 tahun dan belum ada pembaruan untuk komponen cat dinding. Berdasarkan ketentuan PerMen PU Nomor 24/PRT/M/2008 yang menyatakan "cat dinding bangunan penting untuk penampilan bangunan". Pemeliharaan gedung sebaiknya dilakukan pengecatan ulang pada tembok bangunan setiap 2 (dua) atau 3 (tiga) tahun sekali.

Hal yang sama juga di terapkan pada penelitian Adriansyah, (2013) yang melihat Estimasi Biaya Pemeliharaan Bangunan didasarkan Pedoman Pemeliharaan dan Perawatan Bangunan Gedung 
(Studi Kasus Bangunan Masjid Islamic Center Bangkinang). Pada penelitian tersebut, bagi pekerjaan pengecatan dinding termasuk biaya terbesar dengan harga Rp.40.887.618,16,- dengan biaya perbaikan keseluruhan komponen gedung Rp.179.375.561,29,-. Bangunan tersebut sangat penting melakukan perawan khusus, apalagi usia bangunan tersebut lebih dari 3 tahun menurut ketentuan PerMen PU Nomor 24/PRT/M/2008.

Melihat kondisi Kantor Pelayanan Bea dan Cukai Pekanbaru, kondisi tersebut dikategorikan kedalam kerusakan ringan dengan angka $0,1407 \%$. Berdasarkan penelitian yang di lakukan oleh Adriansyah, (2013) dengan analisa harga perbaikan kerusakan komponen bangunan sebesar Rp.179.375.561,29,- total kerusakan 0,66\% yang di peroleh dari perhitungan menggunakan estimasi harga perkiraan taksiran kasar (approximate estimate).

Kesimpulan dari penelitian tersebut bahwa jika ada kesamaan dalam menentukan hasil kerusakan bangunan, yaitu hasil yang sama dibawah $<35 \%$ kerusakan bangunan di katagorikan kedalam kerusakan ringan. Tapi bukan berarti kerusakan ringan dalam suatu penelitian yang penulis analisa, perawatan tidak perlu dilakukan. Karena berdasarkan PerMen PU Nomor 24/PRT/M/2008 menegaskan dalam mempertahankan suatu kondisi bangunan gedung perlu dilakukannya pemeliharaan yang serius agar umur rencana dari bangunan dapat tercapai dan dapat menimalisir kerusakan-kerusakan yang terjadi pada bangunan gedung.

Dan hasil perhitungan yang memprediksi biaya pemeliharaan di tahun 2020 pada bangunan gedung Kantor Pelayanan Bea dan Cukai Pekanbaru dengan biaya sebesar Rp.319,792,000.00 per tahunnya. mengunakan metode ekuivalensi dengan pendekatan nilai masa datang (future value) yang di pengaruhi inflasi tahunan dapat dikatakankan ratarata Peningkatan harga pemeliharaan per tahun dan anggaran biaya pemeliharaan pada 10 tahun kedepan tepatnya pada tahun 2029 adalah sebesar Rp.431.978.231,52,-. Sedangkan pada penelitian Riandika,N (2015) Estimasi suatu biaya pemeliharaan bangunan harus berdasarkan pada pedoman pemeliharaan dan perawatan bangunan gedung (Studi kasus gedung perpustakaan wilayah soeman H.S Pekanbaru) dan perhitungan biaya pemeliharaan di tahun 2015 sebesar Rp.1.881.364.861,11,-. Biaya tersebut di prediksi mengalami peningkatan setiap tahun nya di sebabkan oleh faktor inflasi yang mempengaruhi nilai uang dan nilai bahan yang di gunakan untuk pemeliharaan dan perawatan gedung. Berdasarkan hasil analisa 10 tahun yang akan datang besaran anggaran biaya pemeliharaan tersebut meningkat menjadi sebesar Rp.3.243.771.781,29,-. dan penelitian yang dilakukan oleh Fery, L., (2015) juga memprediksi biaya pemeliharaan di tahun 2016 pada bangunan gedung kantor Bupati Kampar dengan biaya sebesar Rp.2.408.379.210,60,- serta biaya pemeliharaan pada 10 tahun kedepan tepatnya pada tahun 2024 sebesar Rp 5.279.889.743,40,-. Tapi besaran biaya yang telah di analisis hanya sebatas estimasi atau perkiraan, hal tersebut di sebabkan inflasi bisa mengalami kenaikan secara derastis yang dikarenakan oleh berbagai factor.

Dari hasil analisis diatas, semua penelitian tersebut mengacu pada PerMen PU Nomor 24/PRT/M/2008 tentang pedoman pemeliharaan dan perawatan bangunan gedung. Kegunaan Pedoman pemeliharaan dan perawatan bangunan gedung untuk mendapatkan hasil nilai yang terbaik dalam melakukan penjagaan dan keutuhan serta kelayakan dari bangunan tersebut.

\section{KESIMPULAN}

\subsection{Kesimpulan}

Berdasarkan hasil analisa data dan pembahasan ini, maka dapat diambil kesimpulan sebagai berikut :

1. Dari hasil perhitungan rencana anggaran biaya (RAB) untuk perawatan kompone arsitektur pada bangunan Kantor Pelayanan Bea Cukai Pekanbaru di dapat biaya estimasi harga perkiraan taksiran kasar (approximate estimate) sebesar Rp.16.156.679,93 jika dibandingkan dengan perhitungan harga bangunan sebesar Rp.11.483.051.200 persentase biaya untuk perawatan pemeliharaan bangunan Kantor Pelayanan Bea dan Cukai Pekanbaru hanya sebesar 0,1407\% dari total harga bangunan.

2. Besarnya anggaran biaya pemeliharaan yang diperoleh pada Kantor Pelayanan Bea dan Cukai Pekanbaru pada Tahun 2020 sebesar Rp.319,792,000.00, jika mengacu pada nilai inflasi berdasarkan Bank Indonesia dan factor bunga majemuk pada Tahun ke 10 nilai pemeliharaan akan meningkat menjadi sebesar Rp.431.978.231,52,-

4.2 Saran

Berdasarkan seluruh hasil perhitungan yang di peroleh serta survei yang telah dilakukan sebelumnya, maka penulis ingin menyarankan beberapa hal, sebagai berikut :

1. Kepada pihak pengelolah Kantor Pelayanan Bea dan Cukai Pekanbaru, dalam membuat program kerja pemeliharaan, akan lebih baiknya dibuat data base penggantian komponen bangunan, sehingga umur setiap komponen dapat diperkirakan. Data tersebut dapat digunakan untuk prediksi biaya yang dibutuhkan pada tahun mendatang.

2. Supaya penelitian yang dilakukan pada masa yang akan datang dapat menggunakan metode survei dan analisa yang berbeda dengan yang 
penulis lakukan sekarang, hal tersebut disarankan agar mendapatkan cara yang lebih efektif dan bervariasi lagi dan hasil yang diperoleh juga akan semakin akurat.

3. Keakuratan, kemudaahan dalam pemilihan metode estimasi biaya dan yang paling penting adalah tidak mahal dalam penggunaannya, hal tersebut karena diperlukan pertimbangan yang matang dan juga perbandingan analisa yang paling mendekati akurat, agar maksud dari pengertian approximate estimate benar-benar didapatkan.

\section{DAFTAR PUSTAKA}

[1] Adriansyah, 2013, Estimasi Biaya Pemeliharaan Bangunan Berdasarkan Pedoman Pemeliharaan Dan Perawatan Bangunan Gedung (Permen Nomor:24/Prt/M/2008) Studi Kasus Bangunan Masjid Islamic Center Bangkinang, JomFteknik, Vol.1 No.2, pp.1-15, ISSN : 2355-6870.

[2] Aresande, R.F.,2013,Manajemen Perawatan dan Perbaikan Bangunan Gedung Utama Rumah Sakit Umum Daerah (RSUD) Arifin Achmad Pekanbaru Provinsi Riau,Skripsi, Teknik Sipil Politeknik Negeri Bandung. Bandung.

[3] Bank Indonesia, 2018, LaporanInflasi (Indeks Harga Konsumen) BerdasarkanPerhitunganInflasiTahunan 20182019, di akses pada tanggal 2 Januari 2020 http://www.bi.go.id/id/moneter/inflasi/data/Defa ult.aspx.

[4] Badan Standarisasi Nasional, 2008, SNI 7395. 2008 Tata Cara Perhitungan Harga Satuan Pekerjaan Penutup Lantai dan Dinding untuk Konstruksi Bangunan Gedung dan Perumahan, BSN, Jakarta.

[5] Badan Pengelola Keuangan dan AsetKota Pekanbaru, 2019, Standar Harga Barang Dan Jasa Pemerintah, BPKAD, Pekanbaru

[6] Departemen Pemukiman dan Prasarana Wilayah, Pt T-30-2000-C. 2000. Tata Cara Perhitungan Harga Satuan Pekerjaan Kunci, Alat Gantungan dan Kaca untuk Bangunan Rumah dan Gedung.

[7] Fery, L.,2016, Estimasi Biaya Pemeliharaan Bangunan Berdasarkan Pedoman Pemeliharaan Dan Perawatan Bangunan Gedung (Permen Nomor :24/Prt/M/2008) Studi Kasus Bangunan Gedung Kantor Bupati Kampar, Jom F teknik, Vol.3 No.1, pp.1-12, ISSN :2355-6870.

[8] Ibrahim, B., 2001, Rencanadan Estimate Real of Cost, BumiAksara, Jakarta.

[9] Keputusan Walikota Pekanbaru, 2018, Nomor 535 Tahun 2018 Tentang Penetapan harga satuan bangunan gedung Negara, KWP, Pekanbaru.
[10] Mulyandari, H., dan Saputra, R.A., 2011,Pemeliharaan Bangunan: Basic Skill Facility Management, Andi, Yogyakarta.

[11]Mangitung, D., 2013, Ekonomi Rekayasa Disertai Cara Penyelesaian Dengan Spreadsheet, Andi, Yogyakarta.

[12] Nugraha, R., 2015, Estimasi Biaya Pemeliharaan Bangunan Berdasarkan Pedoman Pemeliharaan dan Perawatan Bangunan Gedung (Permen Nomor:24/Prt/M/2008), JomFteknik, Vol.2 No.2, pp.1-11, ISSN : 2355-6870.

[13] Puryani. Agus, R., 2011, Ekonomi Teknik, Graha Ilmu, Yogyakarta.

[14]Peraturan Menteri Pekerjaan Umum, 2010, Nomor : 16/PRT/M/2010 Tentang Pedoman Teknis Pemeriksaan Berkala Bangunan Gedung, PerMen PU, Jakarta.

[15]Peraturan Menteri Pekerjaan Umum, 2008, Nomor : 24/PRT/M/2008 Tentang Pedoman Pemeliharaan dan Perawatan Bangunan Gedung, PerMen PU, Jakarta.

[16]Peraturan Menteri Pekerjaan Umum, 2018, Nomor: 45/PRT/M/2018 Tentang Pedoman Pembangunan BangunanGedung Negara, PerMen PU, Jakarta.

[17]Peraturan Menteri Pekerjaan Umum, 2016, Nomor : 28/PRT/M/2016 Analisis Harga Satuan Pekerjaan Bidang Pekerjaan Umum, PerMen PU, Jakarta.

[18]Reonaldho, M., 2015, Perencanaa Biaya Pemeliharaan dan Perawatan Bangunan Gedung Rumah Sakit Universitas Riau Berdasarkan Permen (NO.24/PRT/M/2008) Jom F teknik, Vol.2 No.2, pp.1-11, ISSN : 2355-6870.

[19]Riandika, N., 2015, Estimasi Biaya Pemeliharaan Bangunan Berdasarkan Pedoman Pemeliharaan dan Perawatan Bangunan Gedung (Permen Nomor:24/Prt/M/2008)Studi Kasus Gedung Perpustakaan Wilayah Soeman H.S Pekanbaru, Jom Fteknik, Vol.1 No.2, pp.111,ISSN2355-6870.

[20]Riana, A.(2012). Analisa Tingkat Kerusakan Dan Estimasi Biaya Perbaikan Banguan Gedung Sekolah,Pekanbaru.

[21] Susanta, G., 2009, Cara Cepat Menghitung Biaya Bangunan Rumah, Penebar Swadaya, Jakarta.

[22] Triatmodjo, B., 2002, Metode Numerik, Beta Offset, Yogyakarta.

[23] Taufik, Hendra. 2009, Tabel-Tabel Bunga Majemuk. Pekanbaru, Teknik Sipil Universitas Riau

[24]Usman, K., 2009, Kajian Manajeman Pemeliharaan Gedung (Building Maintenance) di Universitas Lampung, Jurnal Teknik Sipil dan Perencanaan, Vol.13 No.2, Pp.1-12, ISSN : 2715-0690. 